7. Lumbiganon P, Laopaiboon M, Gülmezoglu AM, et al; World Health Organization Global Survey on Maternal and Perinatal Health Research Group. Method of delivery and pregnancy outcomes in Asia: the WHO global survey on maternal and perinatal health 2007-08. Lancet 2010;375:490-9.

doi: 10.3122/jabfm.2015.01.140269

The above letter was referred to the author of the article in question, who offers the following reply.

\section{Response: Re: Promotion of Family-Centered Birth with Gentle Cesarean Delivery}

To the Editor: We thank Dr. Pust for his comments and for reiterating the goal of promoting vaginal birth as the ideal mode of delivery whenever possible.

The context of our gentle cesarean work is a small urban hospital caring for a largely underserved population, including many high-risk obstetric patients. All well babies are placed skin-to-skin after birth regardless of the mode of delivery. Rooming-in is the norm-we have renamed the nursery the "procedure and monitoring room" and use it as such. In 2013, 458 deliveries occurred at our hospital; $29 \%$ of these were cesarean births, including $21 \%$ primary cesareans. Vaginal birth after cesarean was successfully achieved in 21 of 24 patients undergoing trial of labor after cesarean. Despite our largely underserved, often highrisk patient population, we are pleased that our primary cesarean rates remain the same or lower than national averages. ${ }^{1}$

We note, however, that these statistics are not a perfect assessment of labor and delivery practices at our facility. In recent years a number of women desiring skin-to-skin contact after a planned cesarean birth have elected to transfer care to our facility toward the end of their pregnancy to participate in our gentle cesarean program, so that they may keep their baby with them in the operating room, assuming no emergencies arise. These women are included in the total and primary cesarean rate listed above.

We agree that cesarean delivery is a major surgery and should not be recommended as the mainstay. Yet when operative birth is needed, and mother and baby are healthy, we urge providers and hospital administrators to consider the benefits of the family-centered approach to cesarean delivery that we detailed in our article. ${ }^{2} \mathrm{We}$ believe early skin-to-skin contact between mother and child is possible for most cesarean deliveries and is a potentially important step in the bonding process, in achieving a successful early latch, and in helping to promote sustained breastfeeding.

Sincerely,

$$
\begin{array}{r}
\text { Susanna Magee, MD, MPH } \\
\text { Cynthia Battle, PhD } \\
\text { John Morton, MD } \\
\text { Melissa Nothnagle, MD, MSc } \\
\text { Brown University } \\
\text { Alpert Medical School } \\
\text { Providence, RI }
\end{array}
$$

\section{References}

1. Osterman MJK, Martin JA. Primary cesarean delivery rates, by state: results from the revised birth certificate, 2006-2012. Natl Vital Stat Rep 2014;63:1-11.

2. Magee SR, Battle C, Morton J, Nothnagle M. Promotion of family-centered birth with gentle cesarean delivery. J Am Board Fam Med 2014;27:690-3.

doi: 10.3122/jabfm.2015.01.140315

\section{Re: Family Physicians' Knowledge of Commonly Overused Treatments and Tests}

To the Editor: Maurer et $\mathrm{al}^{1}$ outlined the results of a simple yet elegant study that shows family physicians' knowledge of commonly overused treatments and tests. At first glance, the article seems to demonstrate important gaps in knowledge; however, a detailed reading of the article gives cause for doubt.

Maurer et $\mathrm{al}^{1}$ and the fournal of the American Board of Family Medicine should be lauded for publishing the actual multiple choice questions used in the study in the appendix of the article. Unfortunately, all the questions leave room for improvement. The second question offers the learner a binary choice: yes or no. Someone with no medical knowledge would have a $50 \%$ chance of getting this question correct. The test-wise candidate-who knows that he or she is undergoing an assessment to test his or her ability to "choose wisely"-might also feel prompted to give the answer that the examiner expects, and might thus choose the option with the least number of treatments or tests. The remaining questions ask the candidate to choose the most appropriate scenario for the question. Once again, this is less than optimal as it doesn't simulate clinical reality. Questions should ideally mimic clinical practice-hardly ever in clinical primary care medicine do 4 patients in a row present in relation to a possible Papanicolaou test (as in question 3). The other questions contain similar issues. These problems might seem minor; however, they may create questions that are not as valid and reliable as they should be. The art and science of constructing test questions has advanced over many years, and ignoring the advances that have been made seems a shortcoming. ${ }^{2}$

The good news is that the core content of the questions is likely to be sound and that judicious editing will make them valid and reliable. The questions could then be used in a variety of contexts outside the framework of the study. The questions, or questions like them, could be used efficiently and at low cost in formative or summative assessments, E-learning resources, or simply in promotional campaigns aiming to encourage wiser choices among physicians. ${ }^{3}$ Increasingly, the single best answer to such questions might be no investigation, no drug treatment, and no surgery.

Kieran Walsh BMJ Learning London, UK kmwalsh@bmj.com 